\title{
openheart Agatston score of the descending aorta is independently associated with coronary events in a low-risk population
}

\author{
Elton A M P Dudink, ${ }^{1}$ Frederique E C M Peeters, ${ }^{1}$ Sibel Altintas, ${ }^{1}$ \\ Luuk I B Heckman, ${ }^{1}$ Rutger J Haest, ${ }^{2}$ Hans Kragten, ${ }^{3}$ Bas L J H Kietselaer, ${ }^{1,4}$ \\ Joachim Wildberger, ${ }^{4}$ Justin G L M Luermans, ${ }^{1}$ Bob Weijs, ${ }^{1}$ Harry J G M Crijns ${ }^{1}$
}

To cite: Dudink EAMP, Peeters FECM, Altintas S, et al. Agatston score of the descending aorta is independently associated with coronary events in a low-risk population. Open Heart 2018;5:e000893. doi:10.1136/ openhrt-2018-000893

Received 25 June 2018 Revised 3 0ctober 2018 Accepted 10 November 2018

Check for updates

(C) Author(s) (or their employer(s)) 2018. Re-use permitted under CC BY-NC. No commercial re-use. See rights and permissions. Published by BMJ.

${ }^{1}$ Department of Cardiology, Maastricht University Medical Center (MUMC+) and Cardiovascular Research Institute Maastricht (CARIM), Maastricht, The Netherlands 2Department of Cardiology, St. Anna Hospital, Geldrop, The Netherlands

${ }^{3}$ Department of Cardiology, Zuyderland Medical Center, Heerlen, The Netherlands ${ }^{4}$ Department of Radiology and Nuclear Medicine, Maastricht University Medical Center (MUMC+) and Cardiovascular Research Institute Maastricht (CARIM), Maastricht, The Netherlands

Correspondence to Dr Elton A M P Dudink; elton. dudink@mumc.nl

\section{ABSTRACT}

Objectives A standard coronary artery calcium scan includes part of the aorta. This additional information is often not included in routine analyses. We aimed to determine the feasibility of assessing the Agatston score of the descending aorta calcification (DAC) on standard coronary calcium scans and the association of this score with coronary events in a low-risk study population. Methods Between January 2008 and March 2011, 390 consecutive patients who were referred for cardiac CT as part of work-up for pulmonary vein isolation $(n=115)$ or assessment of presence of coronary artery disease $(n=275)$ were included. At baseline, all patients were free of a history of cardiovascular disease. Two independent observers determined the Agatston score of the ascending aorta and descending aorta.

Results A total of 16 patients (4.1\%) developed coronary events (acute coronary syndrome $(n=6)$ and symptomatic significant coronary artery disease requiring treatment $(n=10))$ during a follow-up of $67 \pm 12$ months, with more events in patients with calcifications in the descending aorta than in those without $(8.4 \%$ vs $3.7 \%$; $p=0.08)$. Multivariable Cox regression, corrected for Framingham Risk Score (FRS) and coronary Agatston score (CAC), revealed that $\mathrm{DAC}$ was independently associated with coronary events (per 100 units; HR: 1.06, 95\% Cl 1.02 to $1.09 ; p=0.001)$. DAC furthermore increased the identification of patients that will experience a coronary event (area under the curve: 0.68 for FRS only, 0.75 for $\mathrm{FRS}+\mathrm{CAC}$ and 0.78 for $\mathrm{FRS}+\mathrm{CAC}+\mathrm{DAC}$ ).

Conclusions The Agatston score of the descending aorta could be included in the standard analysis of cardiac CT scans of low-risk patients since it holds valuable information for the prediction of coronary events.

\section{INTRODUCTION}

Determination of the presence and extent of coronary artery calcium (CAC) on cardiac CT is currently used to stratify the risk of future coronary heart disease (CHD), on top of clinical risk scores. The standard CAC scan includes parts of the ascending and descending aorta, which can also be analysed for the presence of calcifications (thoracic aorta calcification (TAC), consisting of

\section{Key questions}

What is already known about this subject?

- A first assessment of a patient's risk of future coronary events can be done using the Framingham Risk Score. In addition, coronary CT angiography, including coronary calcium scoring scanning, can be used to assess the risk of future coronary events in patients at medium risk for these events. As the radiation dose needed for a coronary calcium score is rapidly decreasing using new techniques, this technique could be used in lower risk patients.

What does this study add?

- Addition of the Agatston score of the descending aorta to the Framingham Risk Score and the coronary Agatston score further improves the prediction of the incidence of coronary events in a low-risk population.

How might this impact on clinical practice?

- Future clinical studies should show whether improved identification of patients at risk for coronary events, using descending aorta Agatston score, could prevent coronary events in these patients by initiation of lifestyle changes and vascular protective therapy.

ascending aorta calcification (AsAC) and descending aorta calcification (DAC)), leading to further information on the vascular status without an increase in radiation dose.

The presence of TAC has been shown to correlate with age, systolic blood pressure, smoking and high levels of low-density lipoprotein-cholesterol. ${ }^{1}$ Previous studies have shown varying results for the value of TAC in predicting future coronary events in intermediate-risk clinical populations, ${ }^{2}$ heavy smokers who were screened for lung carcinoma $^{3}$ and large population-based studies. ${ }^{45}$ It is, however, not known whether aortic calcification precedes the occurrence of coronary events in a low-risk population without a history of overt vascular disease. 
In this paper, we present data on the value of TAC, AsAC and DAC in predicting future clinical coronary artery disease $(\mathrm{CAD})$ in a low-risk population of young age, without hypertension and hypercholesterolaemia, without a history of cardiovascular disease, referred for a CT scan as part of work-up for pulmonary vein isolation (PVI) or for the assessment of the presence of CAD. Furthermore, we assess the value of TAC on top of the Framingham Risk Score (FRS) and CAC.

\section{MATERIALS AND METHODS \\ Patient selection}

The patients in this cohort were described previously. ${ }^{6}$ In short, 390 consecutive patients who underwent coronary calcium scanning in our centre between January 2008 and March 2011 were included: 115 patients with atrial fibrillation as part of work-up for PVI and 275 healthy patients in permanent sinus rhythm who underwent cardiac CT to assess the presence of CAD.

Low risk was defined as being free from hypertension (defined as antihypertensive drug use, systolic blood pressure $\geq 140 \mathrm{~mm} \mathrm{Hg}$ or diastolic blood pressure $\geq 90$ mm Hg during CT visit or left ventricular hypertrophy), diabetes mellitus, and hypercholesterolaemia. Statin use was allowed if initiated as primary prevention in absence of hypercholesterolaemia before initiation, and beta blocker and non-dihydropyridine calcium channel blockers use was allowed if initiated as rate control of atrial fibrillation in absence of hypertension before initiation of therapy. Patients had no history of CAD, renal dysfunction, stroke, malignancy, thyroid or pulmonary disease and no evidence of structural CVD on echocardiogram, including valvular heart disease. Angina or abnormal stress test were never an indication for CT; all patients were asymptomatic. All patients underwent transthoracic echocardiography at baseline.

\section{Computed tomography}

At baseline, a prospective unenhanced coronary calcium scan was performed in all patients as described previously. ${ }^{6}$ Scans performed with a Philips Brilliance 64-slice CT scan were analysed with dedicated EBW Heartbeat CS software (Philips Healthcare, Best, the Netherlands). Scans performed with a Siemens Somatom Definition Flash 2*128-slice CT scan were analysed with syngo.via software (Siemens Healthcare, Forchheim, Germany). The tube current was 240-400 mA (depending on body weight) at $80-120 \mathrm{kV}$. Aortic annulus diameter was measured at the hinge points of the valve leaflets. Aortic sinus diameter, sinotubular junction diameter and ascending aorta diameter were measured at their respective maximum diameters, and descending aorta diameter was measured at the level of the pulmonary artery bifurcation. ${ }^{7}$

Two independent observers determined the Agatston score of the ascending and descending aorta. Calcium present above the origin of the right coronary artery to the end of scan range or up to the origin of the brachiocephalic artery was considered to be localised in the ascending aorta and calcium present distal from the origin the left subclavian artery up to the diaphragm in the descending aorta. The Agatston scores were calculated using a $3 \mathrm{~mm}$ CT slice thickness and detection threshold $\geq 130$ Hounsfield units involving $\geq 1 \mathrm{~mm}^{2}$ area/ lesion (three pixels). ${ }^{8}$ All terminology was used in accordance with recommendations by the Society of Cardiovascular Computed Tomography. ${ }^{9}$

\section{Echocardiographic examination}

At baseline, all patients underwent echocardiography, consisting of a standard two-dimensional echocardiogram, including M-mode and Doppler echocardiography (Sonos 5500, Philips Medical Systems, Andover, Massachusetts, USA) during continuous ECG monitoring according to the recommendations as described in the American Society of Echocardiography guidelines. ${ }^{10}$

\section{Follow-up}

The primary end point-occurrence of coronary events during follow-up-was defined as acute coronary syndrome or stable angina, requiring percutaneous coronary intervention, coronary bypass grafting or medical treatment. The end point was obtained and cross-checked by two independent observers; in case of discrepancies, consensus was reached. Data were derived from patient records as kept by the (referring) hospital and general practitioner.

\section{Statistical analyses}

Statistical analyses were performed using SPSS statistical software (IBM SPSS statistics V.23.0). Correlations are presented as Pearson's $r$ and $p$ value. Continuous variables are presented as mean $\pm \mathrm{SD}$ and are compared with an independent t-test (two tailed) for normally distributed variables and as median with IQR and compared using Mann-Whitney test (two tailed) for not-normally distributed variables. Agatston scores were not transformed as they remain skewed due to many patients having a score of zero and to retain clinical usability. Categorical variables are reported as number of patients and percentage and compared using $\chi^{2}$ testing or two-tailed Fisher's exact test in case of an expected count below 5 . Event rates are shown as events per 1000 patient years and compared using Z-scores. All baseline and CT characteristics were tested for a relation with the occurrence of coronary events during follow-up using univariable Cox regression. All significant covariates were included in multivariable Cox regression. Results were checked for collinearity and interaction among covariates. Manual backwards elimination was used to construct the final models (retention level set at 0.10 ). Proportional hazards were checked. HRs and $95 \%$ CIs were calculated. The discriminatory abilities of the models were assessed using c-statistics and compared using Net Reclassification Index (NRI) and Integrated Discrimination Improvement (IDI), for patients with and without events separately. A p value 

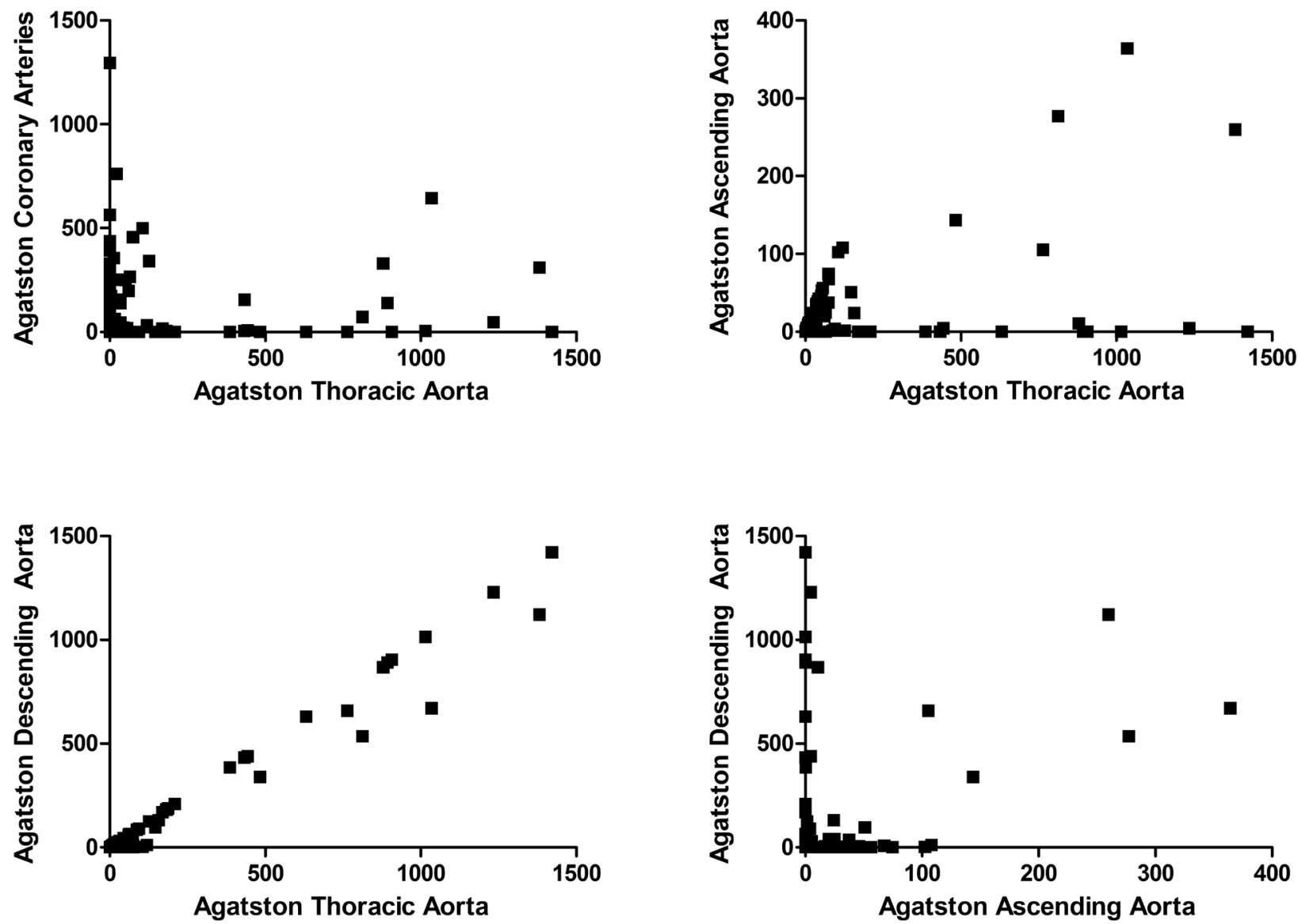

Figure 1 There is a weak correlation between the Agatston score of the thoracic aorta and the Agatston score of the coronary arteries, as there are patients with coronary calcification but no aortic calcification and vice versa (top left; $r=0.016, p=0.001$ ). The Agatston score of the thoracic aorta is partly explained by the Agatston score of the ascending aorta (top right; $r=0.499$, $\mathrm{p}<0.001$ ), but mainly by the Agatston score of the descending aorta (bottom left; $r=0.997, p<0.001$ ). In some patients, there is a correlation between the Agatston score of the ascending aorta and descending aorta, while others have no calcium in the ascending aorta but do have a high Agatston score of the descending aorta (bottom right; $r=0.425, p<0.001$ ).

of 0.05 was considered statistically significant. The first author had full access to all the data in the study and takes responsibility for its integrity and the data analysis.

\section{RESULTS}

Follow-up was complete in 327 patients; the other patients $(n=63)$ were considered lost to follow-up. Patients in whom follow-up was not complete did not differ significantly from the study patients on baseline characteristics (data not shown).

The median Agatston score of the thoracic aorta was 0 (IQR 4.72, range 0-1421), of the ascending aorta was 0 (IQR 0, range 0-364) and of the descending aorta was 0 (IQR 0.24, range 0-1421). TAC was mainly determined by the DAC, reflected by a very strong correlation between TAC and DAC $(\mathrm{r}=0.997 ; \mathrm{p}<0.001)$. AsAC correlated less strongly with both DAC $(\mathrm{r}=0.425 ; \mathrm{p}<0.001)$ and TAC $(\mathrm{r}=0.499 ; \mathrm{p}<0.001)$, as there was a subset of patients that show calcification of the descending aorta but not of the ascending aorta (figure 1). There was a significant yet weak correlation between CAC and TAC ( $r=0.16$; $\mathrm{p}=0.001)$.

On average, patients with calcifications in the ascending aorta were older $(60.1 \pm 6.9$ years vs $53.8 \pm 10.4$ years; $\mathrm{p}<0.001)$, more often female $(46.2 \%$ vs $29.8 \%$; $=0.01)$ and used more statins $(17.9 \%$ vs $6.9 \% ; \mathrm{p}<0.001)$ than those without (table 1).

Patients with calcifications in the descending aorta were also on average older $(61.1 \pm 7.2$ years vs $53.4 \pm 10.0$ years; $\mathrm{p}<0.001)$ and more often female $(44.6 \%$ vs $30.3 \%$; $\mathrm{p}=0.02)$ than those without. Echocardiography showed a smaller end diastolic volume $(108 \pm 253 \mathrm{~mL}$ vs $118 \pm 27 \mathrm{~mL}$; $\mathrm{p}=0.03)$.

CT showed a smaller aortic valve diameter and a higher coronary Agatston score both in patients with calcifications in the ascending $(26 \pm 3 \mathrm{mmvs} 27 \pm 3 \mathrm{~mm}, \mathrm{p}=0.001 ; 0$ IQR 1.38 vs 36 IQR 296, $\mathrm{p}=0.002$ ) and descending aorta (26 $\pm 2 \mathrm{~mm}$ vs $27 \pm 3 \mathrm{~mm}, \mathrm{p}<0.001$; 0 IQR 4.90 vs 0 IQR 198, $\mathrm{p}=0.001)$ than in those without. 
Table 1 Characteristics and events in patients with and without calcification in the ascending and descending aorta

\begin{tabular}{|c|c|c|c|c|c|c|}
\hline & AsAC- $(n=248)$ & AsAC+ $(n=78)$ & $P$ values & DAC- $(n=244)$ & $\mathrm{DAC}+(\mathrm{n}=83)$ & P values \\
\hline \multicolumn{7}{|l|}{ Demographics } \\
\hline Age (years) & $53.8 \pm 10.4$ & $60.1 \pm 6.9$ & $<0.001$ & $53.4 \pm 10.0$ & $61.1 \pm 7.2$ & $<0.001$ \\
\hline Sex (female) & $74(29.8)$ & $36(46.2)$ & 0.01 & $74(30.3)$ & $37(44.6)$ & 0.02 \\
\hline $\begin{array}{l}\text { Systolic blood pressure } \\
(\mathrm{mm} \mathrm{Hg})\end{array}$ & $126 \pm 11$ & $126 \pm 11$ & 0.22 & $126 \pm 11$ & $126 \pm 10$ & 0.59 \\
\hline $\begin{array}{l}\text { Diastolic blood pressure } \\
(\mathrm{mm} \mathrm{Hg})\end{array}$ & $80 \pm 10$ & $79 \pm 10$ & 0.53 & $80 \pm 10$ & $79 \pm 12$ & 0.31 \\
\hline $\mathrm{BMI}\left(\mathrm{kg} / \mathrm{m}^{2}\right)$ & $26(3)$ & $26(6)$ & 0.09 & $26(5)$ & $27(4)$ & 0.49 \\
\hline $\mathrm{BSA}\left(\mathrm{m}^{2}\right)$ & $2.01(0.28)$ & $1.93(0.23)$ & 0.08 & $2.00(0.31)$ & $1.95(0.27)$ & 0.07 \\
\hline \multicolumn{7}{|l|}{ Medical history } \\
\hline $\mathrm{AF}$ & $81(32.7)$ & 21 (26.9) & 0.34 & $81(33.2)$ & $21(25.3)$ & 0.18 \\
\hline AF duration (months) & $26(68)$ & $30(87)$ & 0.74 & $18(68)$ & $43(114)$ & 0.05 \\
\hline \multicolumn{7}{|l|}{ Risk factors } \\
\hline Family history CAD & $78(31.5)$ & $25(32.1)$ & 0.92 & $77(31.6)$ & $26(31.3)$ & 0.97 \\
\hline Smoking & $52(21.0)$ & $16(20.8)$ & 0.97 & $51(21.0)$ & $17(20.5)$ & 0.92 \\
\hline \multicolumn{7}{|l|}{ Medication use } \\
\hline VKA & $24(9.7)$ & $10(12.8)$ & 0.43 & $22(9.0)$ & $12(14.5)$ & 0.16 \\
\hline Aspirin & $65(26.4)$ & $19(24.0)$ & 0.68 & $63(26.1)$ & $20(24.7)$ & 0.80 \\
\hline Beta blocker & $57(23.3)$ & $16(21.3)$ & 0.73 & $55(22.9)$ & $19(23.5)$ & 0.92 \\
\hline Digoxin & $5(2.0)$ & $6(8.0)$ & 0.02 & $5(2.1)$ & $6(7.4)$ & 0.02 \\
\hline Non-dihydropyridine CCB & $10(4.1)$ & $2(2.7)$ & 0.57 & $9(3.8)$ & $3(3.7)$ & 0.99 \\
\hline ACE inhibitor & $0(0.0)$ & $0(0.0)$ & - & $0(0.0)$ & $0(0.0)$ & - \\
\hline ARB & $0(0.0)$ & $0(0.0)$ & - & $0(0.0)$ & $0(0.0)$ & - \\
\hline Diuretics & $0(0.0)$ & $0(0.0)$ & - & $0(0.0)$ & $0(0.0)$ & - \\
\hline Dihydropyridine CCB & $0(0.0)$ & $0(0.0)$ & - & $0(0.0)$ & $0(0.0)$ & - \\
\hline Statin & $17(6.9)$ & $14(17.9)$ & 0.004 & $19(7.8)$ & $12(14.5)$ & 0.07 \\
\hline \multicolumn{7}{|l|}{ Echocardiography } \\
\hline Left atrial diameter (cm) & $3.8 \pm 0.5$ & $3.9 \pm 0.4$ & 0.09 & $3.8 \pm 0.5$ & $3.8 \pm 0.5$ & 0.93 \\
\hline IVSd (mm) & $8.5 \pm 0.9$ & $8.4 \pm 1.0$ & 0.65 & $8.5 \pm 1.0$ & $8.6 \pm 1.0$ & 0.50 \\
\hline LVPWd (mm) & $8.5 \pm 0.9$ & $8.5 \pm 1.0$ & 0.98 & $8.4 \pm 1.0$ & $8.5 \pm 0.8$ & 0.37 \\
\hline EDV (ml) & $118 \pm 27$ & $110 \pm 25$ & 0.10 & $118 \pm 27$ & $108 \pm 25$ & 0.03 \\
\hline ESV (ml) & $43 \pm 16$ & $39 \pm 12$ & 0.14 & $43 \pm 15$ & $40 \pm 14$ & 0.24 \\
\hline $\operatorname{LVEF}(\%)$ & $62(9)$ & $63(8)$ & 0.08 & $61(8)$ & $62(6)$ & 0.42 \\
\hline \multicolumn{7}{|l|}{ CT diameters } \\
\hline Diameter AoV (mm) & $27 \pm 3$ & $26 \pm 3$ & 0.001 & $27 \pm 3$ & $26 \pm 2$ & $<0.001$ \\
\hline $\begin{array}{l}\text { Diameters sinus valsalva } \\
(\mathrm{mm})\end{array}$ & $35 \pm 3$ & $34 \pm 3$ & 0.03 & $35 \pm 3$ & $35 \pm 3$ & 0.18 \\
\hline Diameter STJ (mm) & $30 \pm 3$ & $29 \pm 3$ & 0.06 & $30 \pm 3$ & $30 \pm 3$ & 0.19 \\
\hline $\begin{array}{l}\text { Diameter ascending aorta } \\
(\mathrm{mm})\end{array}$ & $32 \pm 4$ & $32 \pm 3$ & 0.94 & $32 \pm 4$ & $32 \pm 3$ & 0.13 \\
\hline $\begin{array}{l}\text { Diameter descending aorta } \\
(\mathrm{mm})\end{array}$ & $27 \pm 2$ & $27 \pm 2$ & 0.26 & $26 \pm 2$ & $27 \pm 2$ & 0.05 \\
\hline $\begin{array}{l}\text { Agatston score coronary } \\
\text { arteries }\end{array}$ & $0(1.38)$ & $36(296)$ & 0.002 & $0(4.90)$ & 0 (198) & 0.001 \\
\hline $\begin{array}{l}\text { Agatston score ascending } \\
\text { aorta }\end{array}$ & - & $23(53)$ & - & $0(0)$ & $1(22)$ & $<0.001$ \\
\hline
\end{tabular}


Table 1 Continued

\begin{tabular}{|c|c|c|c|c|c|c|}
\hline & AsAC- $(n=248)$ & AsAC+ $(n=78)$ & $P$ values & DAC- $(n=244)$ & $\mathrm{DAC}+(\mathrm{n}=83)$ & $P$ values \\
\hline $\begin{array}{l}\text { Agatston score descending } \\
\text { aorta }\end{array}$ & $0[0]$ & $6(87)$ & $<0.001$ & - & $10(334)$ & - \\
\hline \multicolumn{7}{|l|}{ Events } \\
\hline Stenosis $>70 \%$ on CAG & $6(2.4)$ & $4(5.1)$ & 0.13 & $5(2.8)$ & $5(4.8)$ & 0.60 \\
\hline UAP & $1(0.4)$ & $0(0.0)$ & 0.57 & $1(0.4)$ & $0(0.0)$ & 0.56 \\
\hline NSTEMI & $3(1.2)$ & $1(1.3)$ & 0.96 & $3(1.2)$ & $1(1.2)$ & $>0.99$ \\
\hline STEMI & $1(0.4)$ & $0(0.0)$ & 0.57 & $0(0.0)$ & $1(1.2)$ & 0.09 \\
\hline $\begin{array}{l}\text { Patients with coronary } \\
\text { event }\end{array}$ & $11(4.4)$ & $5(6.4)$ & 0.49 & $9(3.7)$ & $7(8.4)$ & 0.08 \\
\hline Medication only & $7(2.8)$ & $3(3.8)$ & 0.98 & $6(2.5)$ & $4(4.8)$ & 0.20 \\
\hline $\mathrm{PCl}$ & $3(1.2)$ & $2(2.6)$ & 0.40 & $3(1.2)$ & $2(2.4)$ & 0.68 \\
\hline CABG & $1(0.4)$ & $0(0.0)$ & 0.57 & $0(0.0)$ & $1(1.2)$ & 0.25 \\
\hline
\end{tabular}

Shown is $n(\%)$, mean \pm SD or median (IQR).

$\mathrm{ARB}$, angiotensin receptor blocker; AoV, aortic valve; AsAC, ascending aorta calcification; BMI, body mass index; BSA, body surface area; CABG, coronary artery bypass grafting; $C A D$, coronary artery disease; CAG, coronary angiogram; CCB, calcium channel blocker; DAC, descending aorta calcification; EDV, end diastolic volume; ESV, end systolic volume; IVSd, interventricular septum diameter; LVEF, left ventricular ejection fraction; LVPWd, left ventricular posterior wall diameter; NSTEMI, non-ST elevation myocardial infarction; PCI, percutaneous coronary intervention; STEMI, ST elevation myocardial infarction; STJ, sinotubular junction; VKA, vitamin K antagonist; uAP, unstable angina pectoris.

$\mathrm{AF}$, atrial fibrillation.

During a median follow-up duration of 67 months, 16 patients experienced a coronary event, with a trend towards a higher number and more severe events in the patients with calcifications in the descending aorta $(8.4 \%$ vs $3.7 \% ; \mathrm{p}=0.08)$. No difference was found in the incidence of coronary events between patients with and without AsAC ( $6.3 \%$ vs $4.4 \%$; $\mathrm{p}=0.49$ ).

\section{DAC in addition to coronary artery calcification}

To further unravel the additional value of DAC over CAC to predict the occurrence of coronary events during follow-up, we analysed the difference in event rate between patients with and without calcifications in the coronary arteries and descending aorta (figure 2). In patients without coronary artery calcification, the event rate was higher in the patients with calcification of the descending aorta than in those without (11.95 per 1000 patient years vs 2.90 per 1000 patient years; $p=0.06$ ), which is comparable with patients with coronary artery calcification without DAC (14.67 per 1000 patient years; $\mathrm{p}=0.77$ ). The event rate in patients with calcification in both coronary arteries and the descending aorta was the highest (18.26 per 1000 patient years).

\section{Prediction of coronary events}

Univariable Cox regression analysis showed a relation with the occurrence of coronary events for the following predictor variables: age, coronary Agatston score, descending aorta Agatston score and the combined Agatston score of the ascending and descending aorta (all continuous) and the FRS. The Pooled Cohort Equations (HR 1.059, 95\% CI 0.983 to 1.138; $\mathrm{p}=0.14$ ) and the Agatston score of the ascending aorta (HR 1.005, 95\% CI
0.998 to $1.013 ; \mathrm{p}=0.14$ ) showed no significant association with the occurrence of coronary events (table 2). Age and the combined Agatston score of the ascending and descending aorta were excluded from the analysis, due to strong correlations with FRS $(r=0.50 ; p<0.001)$ and the Agatston score of the descending aorta $(r=0.99 ; p<0.001)$, respectively. Multivariable Cox analysis regression

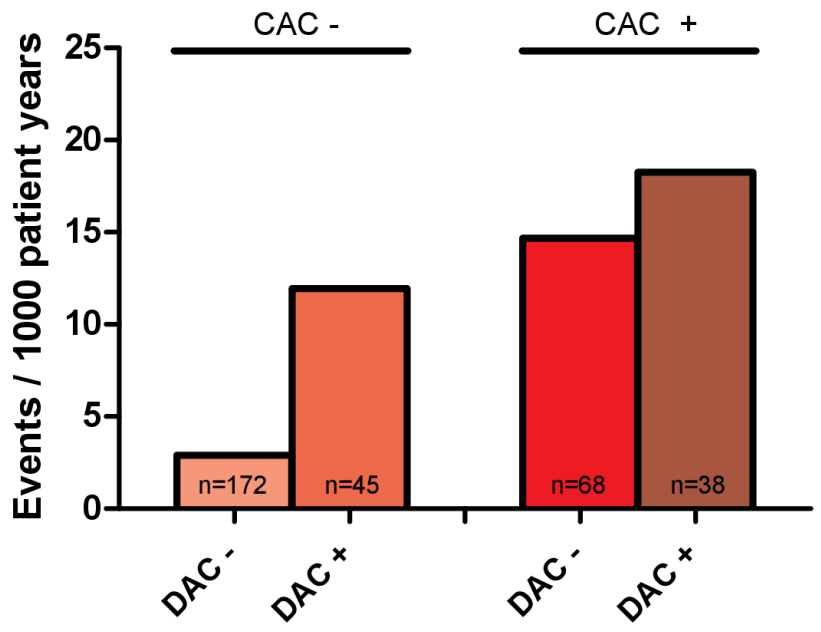

Figure 2 The rate of coronary events per 1000 patient years in patients with and without coronary artery calcification and descending aorta calcification. CAC-, absence of coronary artery calcification; CAC+, presence of coronary artery calcification; DAC-, absence of descending aorta calcification; DAC+, presence of descending aorta calcification. 
Table 2 HRs from univariate and multivariate Cox regression with coronary event during follow-up as endpoint

\begin{tabular}{|c|c|c|c|c|}
\hline & \multicolumn{2}{|l|}{ Univariate } & \multicolumn{2}{|l|}{ Multivariate } \\
\hline & HR $(95 \% \mathrm{Cl})$ & $P$ values & HR $(95 \% \mathrm{Cl})$ & $P$ values \\
\hline Age & 1.09 (1.02 to 1.16$)$ & 0.01 & - & - \\
\hline Agatston coronary arteries (per 100 units) & 1.32 (1.16 to 1.52$)$ & $<0.001$ & $1.30(1.13$ to 1.51$)$ & $<0.001$ \\
\hline Agatston descending aorta (per 100 units) & 1.07 (1.03 to 1.10$)$ & $<0.001$ & $1.06(1.02$ to 1.09$)$ & 0.001 \\
\hline $\begin{array}{l}\text { Agatston combined ascending and descending aorta } \\
\text { (per } 100 \text { units) }\end{array}$ & 1.07 (1.03 to 1.10$)$ & $<0.001$ & - & - \\
\hline Framingham Risk Score & 1.25 (1.07 to 1.46$)$ & 0.005 & 1.24 (1.04 to 1.48$)$ & 0.02 \\
\hline Pooled Cohort Equations & 1.06 (0.98 to 1.14$)$ & 0.14 & - & - \\
\hline
\end{tabular}

Only significant predictors are shown.

revealed that all three remaining parameters are associated with the incidence of coronary events (table 2).

The predictive value of the FRS in this population was moderate (c-statistic: 0.68 ). Addition of the coronary Agatston score improved the c-statistic to 0.75 $(\triangle \mathrm{AUC}+0.07)$, with an improvement in both NRI and IDI for both patients with events and without (NRI ${ }_{\text {events }}$ : $\left.12.5, \mathrm{IDI}_{\text {events }}: 0.38, \mathrm{NRI}_{\text {non-events }}: 73.6, \mathrm{IDI}_{\text {non-events }}: 0.02\right)$. Adding the Agatston score of the descending aorta to this model increased the c-statistic even further to 0.78 $(\triangle \mathrm{AUC}+0.03)$ and further increased NRI for non-events and IDI for both events and non-events (NRI ${ }_{\text {events }}: 0$, IDI vents: $0.24, \mathrm{NRI}_{\text {non-events }}: 65.9, \mathrm{IDI}_{\text {non-events }}: 0.04$; figure 3 ).

\section{DISCUSSION}

This study shows that it is feasible to determine the Agatston score of the thoracic aorta in clinically available cardiac CT scans (with calcium scoring) of low-risk patients that were referred for CAD screening or work-up for PVI. The Agatston score of the descending aorta has predictive value for future coronary events-acute coronary syndrome or symptomatic significant $\mathrm{CAD}$ requiring

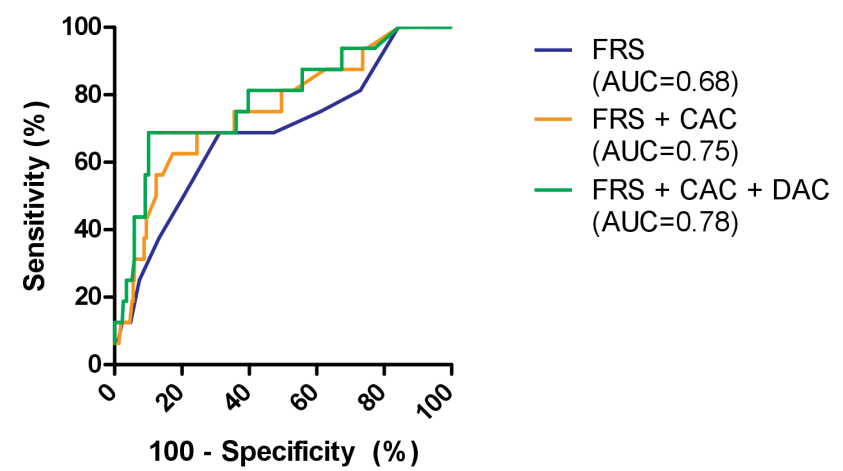

Figure 3 The receiver operating curve of three prediction models for the occurrence of coronary events during 5 years of follow-up: Framingham Risk Score (FRS) only, FRS+the Agatston score of the coronary arteries calcium (CAC) and $\mathrm{FRS}+\mathrm{CAC}+$ the Agatston score of the descending aorta calcification (DAC). AUC, area under the curve. treatment—on top of the FRS and the Agatston score of the coronary arteries.

From our results, one may be hypothesise that aortic calcification is associated with early, subclinical forms of cardiovascular disease processes. As such, the presence of DAC may identify a subgroup of patients that appears healthy clinically yet harbours an early form of cardiovascular disease, explaining why the presence of DAC is associated with future coronary events. As there is little correlation between $\mathrm{CAC}$ and $\mathrm{DAC}$, there might be different processes leading to $\mathrm{CAC}$ on the one hand and DAC on the other.

Both in the Framingham Heart Study and in the Heinz Nixdorff Recall study-a population-based study that aims to improve the prediction of cardiovascular eventsit was shown that TAC predicts incident CAD but that it is outperformed by the coronary Agatston score. ${ }^{11}{ }^{12}$ In the 'Multiethnic study of atherosclerosis' (MESA), aortic calcification was studied intensively: it was shown that TAC only has independent predictive value for incident CAD in women but not in men, ${ }^{4}$ that the number of affected vascular structures is predictive of future events, ${ }^{13} 14$ but that it does not have additional value if no CAC is present. ${ }^{15}$ From the same study, it is known that both incidence and progression of TAC were associated with the presence of traditional clinical risk factors, such as age, hypertension and smoking. ${ }^{16}$ In contrast to the population included in MESA, Framingham Heart Study and in the Heinz Nixdorff Recall study, in our study population, only patients were included that did not yet have any of the traditional cardiovascular risk factors. This further underlines that aortic calcification may be a very early marker of atherosclerosis, suggesting that determining aortic calcification in patients with classical risk factors may be too late, while in low-risk patients, aortic calcification may still identify those patients that soon will develop coronary events.

In previous reports, carotid intima-media thickness (c-IMT) has been proposed as a means to detect subclinical atherosclerosis and thus to use c-IMT to improve risk prediction. ${ }^{17}$ However, a large meta-analysis showed very limited value of c-IMT over the FRS in predicting 
coronary events. ${ }^{18}$ Interestingly, it has been shown that there is only a weak correlation between c-IMT with aortic calcification on $\mathrm{CT},{ }^{19}$ indicating that c-IMT either identifies other pathophysiological processes than TAC or that the stage in which atherosclerosis is detected is different. This report suggests that the assessment of aortic calcification, in combination with coronary calcification, may be a good alternative to c-IMT in predicting coronary events.

Currently, according to European guidelines, CAC should be used in the lower range of pretest probability and mainly in case of doubt about risk category and the associated treatment. ${ }^{20}$ US guidelines indicate that cardiovascular risk prediction in asymptomatic patients using coronary calcium scanning should be used in moderate risk patients ${ }^{21}$ and only for low risk patients with a family history of premature $\mathrm{CAD} .{ }^{17}$ However, in daily practice, $\mathrm{CAC}$ is frequently used in low-risk patients as well. ${ }^{22}$ In this study, we confirm that the predictive value found in moderate risk patients ${ }^{2324}$ also holds true in a low-risk population. The coronary calcium scoring increases the discriminatory value of the FRS, with addition of DAC leading to a further increase. Since the majority of coronary heart disease occurs especially in those patients at low to intermediate risk, aortic and coronary calcium scoring might guide proper prescription of aspirin for primary prevention of CHD in this population. ${ }^{25} \mathrm{Natu}-$ rally, radiation exposure has to be taken into consideration while performing CT calcium scoring in low-risk patients. However, ongoing improvement in CT scanners and advances in radiation dose reduction ${ }^{26}$ have enabled submillisievert cardiac calcium scoring scans, alleviating this concern. It can thus be concluded that the balance might be shifting in low-risk patients as the radiation dose is steadily decreasing, and the prognostic information acquired is increasing through measures such as DAC that are freely available in the acquired images.

These study results were obtained in a relatively small, selected population and should be reproduced. Due to the strict definition of patients free of any form of overt vascular disease, the rates of coronary events during the first 5 years of follow-up are low. Longer follow-up may reveal the use of CT in predicting all major adverse cardiac and cerebrovascular events in low-risk patients. Follow-up CT was not performed routinely, making analysis of the progression of aortic calcification impossible.

\section{CONCLUSION}

It is feasible to determine the Agatston score of the descending aorta in the images acquired during a standard cardiac CT for coronary calcium assessment. The Agatston score of the descending aorta appears to improve the identification of those patients - of both sexes-that will experience coronary events in a low-risk population on top of the combination of clinical risk scores (FRS) and the coronary Agatston score. Future, larger studies should confirm the value of adding the
Agatston score of the descending aorta to the standard analysis of cardiac CT scans of low-risk patients.

Contributors EAMPD, BLJHK, JGLML, BW and HJGMC contributed to the conception or design of the work. All authors contributed to the acquisition, analysis or interpretation of data for the work. EAMPD drafted the manuscript. HJGMC acquired funding. All authors critically revised and approved the manuscript.

Funding We acknowledge the support from the Netherlands Cardiovascular Research Initiative: an initiative with support of the Dutch Heart Foundation, CVON 2014-9: Reappraisal of Atrial Fibrillation: interaction between hyperCoagulability, Electrical remodeling, and Vascular destabilization in the progression of AF (RACE V), and the European Union's Horizon 2020 Research and Innovation Program (CATCH ME - grant number 633196).

Competing interests One author (JW) of this manuscript declares institutional relationships with the following companies: Siemens AG, Bayer Healthcare, Philips, $\mathrm{GE}$, all outside submitted work.

Patient consent for publication Not required.

Ethics approval IRB academic Hospital Maastricht/Maastricht University.

Provenance and peer review Not commissioned; externally peer reviewed.

Data sharing statement The dataset used and analysed during the current study are available from the corresponding author on reasonable request.

Open access This is an open access article distributed in accordance with the Creative Commons Attribution Non Commercial (CC BY-NC 4.0) license, which permits others to distribute, remix, adapt, build upon this work non-commercially, and license their derivative works on different terms, provided the original work is properly cited, appropriate credit is given, any changes made indicated, and the use is non-commercial. See: http://creativecommons.org/licenses/by-nc/4.0/.

\section{REFERENCES}

1. Kälsch H, Lehmann N, Möhlenkamp S, et al. Prevalence of thoracic aortic calcification and its relationship to cardiovascular risk factors and coronary calcification in an unselected population-based cohort: the Heinz Nixdorf Recall Study. Int J Cardiovasc Imaging 2013;29:207-16.

2. Wong ND, Gransar $H$, Shaw $L$, et al. Thoracic aortic calcium versus coronary artery calcium for the prediction of coronary heart disease and cardiovascular disease events. JACC Cardiovasc Imaging 2009;2:319-26.

3. Willemink MJ, Takx RA, Išgum I, et al. Prognostic value of heart valve calcifications for cardiovascular events in a lung cancer screening population. Int J Cardiovasc Imaging 2015;31:1243-9.

4. Budoff MJ, Nasir K, Katz R, et al. Thoracic aortic calcification and coronary heart disease events: the multi-ethnic study of atherosclerosis (MESA). Atherosclerosis 2011;215:196-202.

5. Mahabadi AA, Lehmann N, Möhlenkamp S, et al. Noncoronary measures enhance the predictive value of cardiac CT above traditional risk factors and CAC Score in the general population. JACC Cardiovasc Imaging 2016;9:1177-85.

6. Weijs B, Pisters R, Haest RJ, et al. Patients originally diagnosed with idiopathic atrial fibrillation more often suffer from insidious coronary artery disease compared to healthy sinus rhythm controls. Heart Rhythm 2012;9:1923-9.

7. Erbel R, Aboyans V, Boileau C, et al. 2014 ESC Guidelines on the diagnosis and treatment of aortic diseases: document covering acute and chronic aortic diseases of the thoracic and abdominal aorta of the adult. The task force for the diagnosis and treatment of aortic diseases of the European Society of Cardiology (ESC). Eur Heart J 2014;35:2873-926.

8. Agatston AS, Janowitz WR, Hildner FJ, et al. Quantification of coronary artery calcium using ultrafast computed tomography. J Am Coll Cardiol 1990;15:827-32.

9. Weigold WG, Abbara S, Achenbach S, et al. Standardized medical terminology for cardiac computed tomography: a report of the Society of Cardiovascular Computed Tomography. J Cardiovasc Comput Tomogr 2011;5:136-44.

10. Douglas PS, Garcia MJ, Haines DE, et al. ACCF/ASE/AHA/ASNC/ HFSA/HRS/SCAI/SCCM/SCCT/SCMR 2011 appropriate use criteria for echocardiography. A report of the American College of Cardiology Foundation Appropriate Use Criteria Task Force, American Society of Echocardiography, American Heart Association, American Society of Nuclear Cardiology, Heart Failure Society of America, Heart Rhythm Society, Society for Cardiovascular 
Angiography and Interventions, Society of Critical Care Medicine, Society of Cardiovascular Computed Tomography, and Society for Cardiovascular Magnetic Resonance Endorsed by the American College of Chest Physicians. J Am Coll Cardiol 2011;57:1126-66.

11. Kälsch $\mathrm{H}$, Lehmann N, Berg MH, et al. Coronary artery calcification outperforms thoracic aortic calcification for the prediction of myocardial infarction and all-cause mortality: the Heinz Nixdorf Recall Study. Eur J Prev Cardiol 2014;21:1163-70.

12. Hoffmann U, Massaro JM, D'Agostino RB, et al. Cardiovascular event prediction and risk reclassification by coronary, aortic, and valvular calcification in the framingham heart study. J Am Heart Assoc 2016;5:e003144.

13. Criqui MH, Denenberg JO, McClelland RL, et al. Abdominal aortic calcium, coronary artery calcium, and cardiovascular morbidity and mortality in the Multi-Ethnic Study of Atherosclerosis. Arterioscler Thromb Vasc Biol 2014;34:1574-9.

14. Tison $\mathrm{GH}$, Guo M, Blaha MJ, et al. Multisite extracoronary calcification indicates increased risk of coronary heart disease and all-cause mortality: The Multi-Ethnic Study of Atherosclerosis. J Cardiovasc Comput Tomogr 2015:9:406-14.

15. Kim J, Budoff MJ, Nasir K, et al. Thoracic aortic calcium, cardiovascular disease events, and all-cause mortality in asymptomatic individuals with zero coronary calcium: the Multi-Ethnic Study of Atherosclerosis (MESA). Atherosclerosis 2017;257:1-8.

16. Youssef G, Guo M, McClelland RL, et al. Risk factors for the development and progression of thoracic aorta calcification: the multi-ethnic study of atherosclerosis. Acad Radiol 2015;22:1536-45.

17. Greenland P, Alpert JS, Beller GA, et al. 2010 ACCF/AHA guideline for assessment of cardiovascular risk in asymptomatic adults: a report of the American College of Cardiology Foundation/American Heart Association Task Force on Practice Guidelines. J Am Coll Cardiol 2010;56:e50-103.

18. Den Ruijter HM, Peters SA, Anderson TJ, et al. Common carotid intima-media thickness measurements in cardiovascular risk prediction: a meta-analysis. JAMA 2012;308:796-803.

19. Kathiresan S, Larson MG, Keyes MJ, et al. Assessment by cardiovascular magnetic resonance, electron beam computed tomography, and carotid ultrasonography of the distribution of subclinical atherosclerosis across Framingham risk strata. Am J Cardiol 2007;99:310-4.
20. Piepoli MF, Hoes AW, Agewall S, et al. 2016 European Guidelines on cardiovascular disease prevention in clinical practice: the Sixth Joint Task Force of the European Society of Cardiology and Other Societies on Cardiovascular Disease Prevention in Clinical Practice (constituted by representatives of 10 societies and by invited experts)Developed with the special contribution of the European Association for Cardiovascular Prevention \& Rehabilitation (EACPR). Eur Heart J 2016;37:2315-81.

21. Greenland $\mathrm{P}$, Bonow RO, Brundage $\mathrm{BH}$, et al. ACCF/AHA 2007 clinical expert consensus document on coronary artery calcium scoring by computed tomography in global cardiovascular risk assessment and in evaluation of patients with chest pain: a report of the American College of Cardiology Foundation Clinical Expert Consensus Task Force (ACCF/AHA Writing Committee to Update the 2000 Expert Consensus Document on Electron Beam Computed Tomography) developed in collaboration with the Society of Atherosclerosis Imaging and Prevention and the Society of Cardiovascular Computed Tomography. J Am Coll Cardiol 2007;49:378-402.

22. Nasir K, Rubin J, Blaha MJ, et al. Interplay of coronary artery calcification and traditional risk factors for the prediction of all-cause mortality in asymptomatic individuals. Circ Cardiovasc Imaging 2012;5:467-73.

23. Detrano R, Guerci AD, Carr JJ, et al. Coronary calcium as a predictor of coronary events in four racial or ethnic groups. $N$ Engl J Med 2008;358:1336-45.

24. Greenland P, LaBree L, Azen SP, et al. Coronary artery calcium score combined with Framingham score for risk prediction in asymptomatic individuals. JAMA 2004;291:210-5.

25. Miedema MD, Duprez DA, Misialek JR, et al. Use of coronary artery calcium testing to guide aspirin utilization for primary prevention: estimates from the multi-ethnic study of atherosclerosis. Circ Cardiovasc Qual Outcomes 2014;7:453-60.

26. Voros S, Rivera JJ, Berman DS, et al. Guideline for minimizing radiation exposure during acquisition of coronary artery calcium scans with the use of multidetector computed tomography: a report by the Society for Atherosclerosis Imaging and Prevention Tomographic Imaging and Prevention Councils in collaboration with the Society of Cardiovascular Computed Tomography. J Cardiovasc Comput Tomogr 2011;5:75-83. 